\title{
Investigating knowledge management critical success factors in carpet industry
}

\author{
Naser Azad, Seyed Mohsen Seyed Aliakbar and Mehdi Ansari*
}

Department of Management, Islamic Azad University, South Tehran Branch, Tehran, Iran

\begin{tabular}{|c|c|}
\hline ARTICLE I NFO & A B S T RAC T \\
\hline $\begin{array}{l}\text { Article history: } \\
\text { Received March 25, } 2012 \\
\text { Received in revised format } \\
25 \text { September } 2012 \\
\text { Accepted } 8 \text { October } 2012 \\
\text { Available online } \\
\text { October } 132012 \\
\text { Keywords: } \\
\text { Factor analysis } \\
\text { Carpet industry } \\
\text { Knowledge management }\end{array}$ & $\begin{array}{l}\text { This paper presents an empirical study to learn more about challenges in carpet industry using } \\
\text { factor analysis. The proposed study of this paper designs a questionnaire consists of } 51 \\
\text { questions in Likert scale and distribute it among experts in Carpet industry. We have analyzed } \\
\text { the data using factor analysis and deleted } 10 \text { most redundant questions. Cronbach alpha was } \\
\text { calculated as } 0.88 \text { for the remaining questions, which is well above the minimum desirable } \\
\text { limit. We have also managed to remove six more questions using principal axis factoring } \\
\text { leaving } 8 \text { basic components including } 35 \text { different questions. The proposed study of this paper } \\
\text { has categorized eight factors including specialized relationships, knowledge coordinator, } \\
\text { knowledge tool, knowledge organization, knowledge processes, knowledge chain, knowledge } \\
\text { hardware and Knowledge feasibility study. Investigating details of the results of each eight } \\
\text { items could help us build better strategies to help this industry grow faster and more reliable in } \\
\text { today's business world. }\end{array}$ \\
\hline
\end{tabular}

\section{Introduction}

Iranian carpet industry has been one of the most popular handcraft industries in the world and it has created substantial numbers of jobs in different villages and small towns in this country. There are literally many designs and plans introduced by Iranian carpet makers but during the past two decades, we have been witness on an increasing competition mostly from other countries such as China, India, Pakistan, etc. On the other hands, there are ongoing interests for membership of world trade organization (WTO). It is important to take the necessary actions to remove any barrier for joining this kind of agreement and knowledge management and intellectual capital play important roles on business units.

Bontis (2001) performed a comprehensive review on the literature pertaining to the evaluation of knowledge assets. He explained that knowledge assets are primary source of sustainable competitive advantage. He also explained the burgeoning field of intellectual capital (IC) as an exciting area for

* Corresponding author.

E-mail addresses: mehdi.ansari83@gmail.com (M. Ansari) 
both researchers and practitioners and argued that the measurement of such intangible assets is challenging task. He discussed various models to measure IC highlighted their strengths, weaknesses.

Anumba (2009) investigated the necessary for next-generation knowledge management (KM) systems in the construction sector. The survey outlined the primary features that such systems definitely needs. According to Anumba (2009), KM has recently becoming to deliver value to many construction sector organizations but there is still a need for next-generation systems, which could provide much more added value.

Dalkir et al. (2007) presented an assessment model for evaluating the success of KM initiatives in a government setting. They reported that the proposed results-based management assessment framework proved to be suitable for KM assessment in a government setting.

Gao et al. (2008) purpose of this research is to help knowledge managers systematically grasp knowledge about management knowledge and presented a deep and full understanding of the nature, scope and methodologies of knowledge management. They reported that KM in business organizations is responsible for managing the activities of knowledge workers or the transformation and interaction of organizational static substance knowledge and dynamic process knowledge for products, services, and practical process innovation and, at the same time, creating new or justifying other organizational systematic knowledge. According to their survey, KM is not just about recording and manipulating explicit knowledge, but requires explaining other issues such as process rather than content.

Gold et al. (2001) investigated the issue of effective KM in terms of organizational capabilities. They reported that a knowledge infrastructure consisting of structure, technology and culture along with a knowledge process architecture of acquisition, application, conversion and protection are essential organizational capabilities or "preconditions" for effective KM. They also provided a basis for understanding the competitive predisposition of a firm as it enters a program of KM through an empirical investigation. Gilak et al. (2012) introduced a new concept about the nonlinear impact of effective tax rate on tax evasion.

Hanisch et al. (2009) demonstrated how KM in temporary organizations has recently becoming increasingly important factor in many industries and examined $\mathrm{KM}$ in different projects. They reported that the success of $\mathrm{KM}$ implementation is mainly determined by cultural factors whereas technical aspects like information systems and project management methods are considered as supporting factors. Kim (2001) studied the impact of cognitive styles on users' information looking for task performance using a knowledge domain information visualization system. Kim reported that users' cognitive styles could influence their search performance. The results confirmed that cognitive style was an important factor in the study of information science and human-computer interaction.

According to Uziene (2010), Intellectual capital (IC) theory has been active for two decades but there are still many unanswered questions in theory and business practices. IC based issues in terms of essence, structure, measurement and its impact on business performance are still subject of many investigations. Managers constantly search for the new solutions of recognizing, measuring and managing IC in order to maximize the value of knowledge, develop new forms of competitiveness and increase organization's potential. Rangriz et al. (2012) implemented various mathematical techniques to consider different actions for changing threats to opportunities, reducing unnecessary 
costs, increasing revenue and market share, etc. They implemented Fuzzy analytical hierarchy process (AHP), Benefits-Opportunities-Costs-Risks (BOCR) technique to detect possible benefit, risk and cost components.

\section{The proposed study}

The proposed study of this paper designs a questionnaire consists of 51 questions in Likert scale and distribute it among experts in Carpet industry. We have analyzed the data using factor analysis and deleted 10 most redundant questions. Cronbach alpha was calculated as 0.88 for the remaining questions, which is well above the minimum desirable limit. We have also managed to remove six more questions using principal axis factoring leaving 8 basic components including 35 different questions.

\section{Details of factor analysis}

\subsection{Specialists}

This item includes 12 main variables including users' commitment, facilitating relationships, organizational structure, using new ideas, effective organization, specialty, leadership, strategy, resource allocation, information exchange, training and education and supply chain management and details of results are given in Table 1 where Cronbach alpha has been calculated as 0.937.

\section{Table 1}

Details of factor analysis specialized relationships

\begin{tabular}{|c|c|c|c|c|}
\hline Option & Factor weight & Eigen value & of variance $\%$ & Accumulated \\
\hline Users' commitment & 0.874 & & & \\
\hline Facilitating relationships & 0.869 & & & \\
\hline Organizational structure & 0.840 & & & \\
\hline using new ideas & 0.795 & & & \\
\hline Effective organization & 0.758 & & & \\
\hline Specialty & 0.756 & 7.434 & 21.240 & 21.240 \\
\hline Leadership & 0.749 & & & \\
\hline Strategy & 0.720 & & & \\
\hline Resource allocation & 0.697 & & & \\
\hline Information exchange & 0.691 & & & \\
\hline Training and education & 0.644 & & & \\
\hline Supply chain management & 0.509 & & & \\
\hline
\end{tabular}

\subsection{Knowledge Coordinator}

Knowledge Coordinator includes four variables including coordinator, competitive advantage, knowledge identification and knowledge organization. Table 2 summarizes details of our results for this item and Cronbach alpha has been calculated as 0.852 .

\section{Table 2}

Factor analysis for Knowledge coordinator

\begin{tabular}{lcccc}
\hline Option & Factor weight & Eigen value & of variance \% & Accumulated \\
\hline Coordinator & 0.942 & & & \\
Competitive advantage & 0.847 & 4.087 & 11.676 & 32.916 \\
Knowledge identification & 0.818 & & & \\
Knowledge organization & 0.720 & & & \\
\hline
\end{tabular}




\subsection{Knowledge tool}

This component includes five variables including intellectual properties, knowledge evaluation, knowledge sharing, information gathering and organizational culture. Cronbach alpha has been calculated as 0.866 and details of factor analysis have been given in Table 3.

\section{Table 3}

Factor analysis for Knowledge tool

\begin{tabular}{lcccc}
\hline Option & $\begin{array}{c}\text { Factor } \\
\text { weight }\end{array}$ & Eigen value & of variance \% & Accumulated \\
\hline Intellectual properties & 0.895 & & & \\
Knowledge evaluation & 0.818 & & & \\
Knowledge sharing & 0.803 & 3.854 & 11.011 & \\
Information gathering & 0.721 & & & \\
Organizational culture & 0.634 & & & \\
\hline
\end{tabular}

\subsection{Knowledge organization}

This item includes four variables including organizational intelligence, employee skills, organizational experience and learning. Cronbach alpha has been calculated as 0.761 and Table 4 shows details of our findings,

\section{Table 4}

Factor analysis for knowledge organization

\begin{tabular}{|c|c|c|c|c|}
\hline Option & Factor weight & $\begin{array}{c}\text { Eigen } \\
\text { value }\end{array}$ & of variance \% & Accumulated \\
\hline Organizational intelligence & 0.802 & & & \\
\hline Employee skills & 0.715 & 2.624 & 7.496 & 51.423 \\
\hline Organizational experience & 0.710 & & & \\
\hline Organizational learning & 0.636 & & & \\
\hline
\end{tabular}

\subsection{Knowledge processes}

This factor includes three variables including knowledge transfer, resource management and knowledge storage and they are analyzed using factor analysis, where Cronbach alpha has been calculated as 0.616 and details are given in Table 5 as follows.

Table 5

The summary of factor analysis for knowledge processes

\begin{tabular}{lcccc}
\hline Option & Factor weight & $\begin{array}{l}\text { Eigen } \\
\text { value }\end{array}$ & $\begin{array}{l}\text { of \% } \\
\text { variance }\end{array}$ & Accumulated \\
\hline Knowledge transfer & 0.796 & & & 57.564 \\
Resource management & 0.604 & 2.150 & 6.142 & \\
Knowledge storage & 0.596 & & & \\
\hline
\end{tabular}

\subsection{Knowledge chain}

This item includes three variables including knowledge database, knowledge based economy and knowledge unification and Cronbach alpha has been calculated as 0.573 and details are given in Table 6. 
Table 6

The summary of factor analysis for knowledge chain

\begin{tabular}{lcccc}
\hline Option & Factor weight & Eige value & \%of variance & Accumulated \\
\hline Knowledge database & 0.809 & & & \\
Knowledge based economy & -0.687 & 2.074 & 5.926 & 63.490 \\
Knowledge unification & 0.653 & & & \\
\hline
\end{tabular}

\subsection{Knowledge hardware}

This item includes two variables knowledge asset and knowledge distribution and Cronbach alpha is calculated as 0.771 and details are given in Table 7 as follows.

Table 7

The summary of factor analysis for knowledge hardware

\begin{tabular}{lcccc}
\hline Option & Factor weight & Eigen value & of variance \% & Accumulated \\
\hline knowledge asset & 0.725 & & & \\
knowledge distribution & 0.578 & 1.720 & 4.913 & 68.403 \\
\hline
\end{tabular}

\subsection{Knowledge feasibility study}

Knowledge feasibility study includes two factors of obtaining knowledge and software applications. Cronbach alpha has been calculated as 0.569 and Table 8 summarizes the results.

\section{Table 8}

The summary of factor analysis for knowledge hardware

\begin{tabular}{lcccc}
\hline Option & Factor weight & $\begin{array}{r}\text { Eigen of } \\
\text { value }\end{array}$ & $\begin{array}{r}\% \\
\text { variance }\end{array}$ & Accumulated \\
\hline obtaining knowledge & 0.903 & & & \\
software applications & -0.667 & 1.524 & 4.354 & 72.758 \\
\hline
\end{tabular}

In summary, we can conclude that there eight important factors influencing knowledge management in carpet industry and each factor includes between two to twelve different factors where the relative importance of each item has been demonstrated in details.

\section{Conclusion}

In this paper, we have presented an empirical study to learn more about challenges in carpet industry using factor analysis. The proposed study of this paper has categorized eight factors including specialized relationships, knowledge coordinator, knowledge tool, knowledge organization, knowledge processes, knowledge chain, knowledge hardware and Knowledge feasibility study. Investigating details of the results of each eight items could help us build better strategies to help this industry grow faster and more reliable in today's business world.

\section{Acknowledgment}

The authors would like to thank the anonymous referees for constructive comments on earlier versions of this paper. 


\section{References}

Anumba, C. J. (2009). Editorial: Towards next-generation knowledge management systems for construction sector organizations. Construction Innovation: Information, Process, Management, 9(3), $245-249$.

Balsara, N., Chen, G., \& Zheng, L. (2005). Momentum strategies: Are they effective in China? Journal of International Business and Economics, 1, 230-239.

Bontis , N. (2001) . Assessing knowledge assets: a review of the models used to measure intellectual capital. International Journal of Management Reviews, 3(1), 41-60.

Choi, B., \& Lee, H. (2003). An empirical investigation of KM styles and their effect on corporate performance, Graduate School of Management, Korea Advanced Institute of Science and Technology, 207-243.

Davel, R., \& Snyman. M. (2007). Influence of corporate culture on the use of knowledge management techniques and technologies. Department of Information Knowledge Management, University of Johannesburg, 6-17.

Dalkir, K., Wiseman, E., Shulha, M., \& McIntyre, S. (2007). An intellectual capital evaluation approach in a government organization. Management Decision, 45(9), 1497 - 1509.

Gao, F., Li, M., \& Clarke , S. (2008). Knowledge, management, and knowledge management in business operations. Journal of Knowledge Management , 12(2), 3 - 17.

Gold, A., Malhotra, A., \& Segars, A.H. (2001). Knowledge management: an organization capabilities perspective. Journal of Management Information System, 18(1), 185-214.

Gilak, M. T., Karimi, P. S. , \& Jafari Samimi, A., \& Aminkhaki, A. (2012). The nonlinear effect of effective tax rate on tax evasion in Iran. American Journal of Scientific Research, 46, 43-46 .

Grundstein, M. \& Rosenthal Sarbroux, C. (2005). Towards a model for global knowledge management within the enterprise (M GKME). Managing Modern Organizations with Information Technology, 32, 1259-1262,

Hanisch, B., Lindner, F., Mueller, A., \& Wald, A. (2009). Knowledge management in project environments. Journal of Knowledge Management, 13(4), 148 - 160.

Kim, K.S. ( 2001). Implications of user characteristics in information seeking. International Journal of Human Computer Interaction, 13(3), 323-340.

Uziene, L. ( 2010). Model of organization's intellectual capital measurement. Inzinerine EkonomikaEngineering Economics, 21(2), 151-159.

Rangriz, H., Hosseinpour, M., \& Esmaeili, S. (2012). A BOCR and Fuzzy AHP method for identification and prioritization of carpet industry strategies. Management Science Letters, 2(8). DOI: $10.5267 / j . m s l .2012 .09 .024$. 